\title{
Nitric oxide-induced potentiation of the killing of Burkholderia cepacia by reactive oxygen species: implications for cystic fibrosis
}

\author{
ANTHONY W. SMITH, JOHN GREEN, CHARLOTTE E. EDEN and MALCOLM L. WATSON \\ Department of Pharmacy and Pharmacology, University of Bath, Claverton Down, Bath BA2 7AY
}

\begin{abstract}
Burkholderia (formerly Pseudomonas) cepacia has emerged as an important pulmonary pathogen in cystic fibrosis, and survives within the lung despite a vigorous neutrophildominated immune response. Nitric oxide (NO) contributes to the antimicrobial activity of reactive oxygen species in the normal lung, but recent evidence suggests that inducible NO synthase is not expressed in the airway epithelial cells of cystic fibrosis (CF) patients. This may explain the failure of the neutrophil response to eliminate $B$. cepacia. To test this hypothesis, the present study examined the combined effect of NO, superoxide and $\mathrm{H}_{2} \mathrm{O}_{2}$ against $B$. cepacia. There was no killing of a highly transmissible strain by either superoxide or NO alone, but their combination reduced the bacterial count by $>1000$-fold over $75 \mathrm{~min}$. This bactericidal activity was not sensitive to addition of superoxide dismutase, but was abrogated completely by catalase, suggesting that NO and hydrogen peroxide were the bactericidal mediators. Increased killing by NO in combination with $\mathrm{H}_{2} \mathrm{O}_{2}$ was seen for seven of a further 11 strains examined. The lack of NO in the lungs of CF patients may contribute to the survival of $B$. cepacia.
\end{abstract}

\section{Introduction}

Cystic fibrosis (CF) is characterised by abnormal mucosal secretions at several sites. The dehydrated mucus in the lungs supports growth and chronic colonisation by bacterial pathogens, notably Staphylococcus aureus, Haemophilus influenzae, Pseudomonas aeruginosa and Burkholderia cepacia. Another major characteristic is inflammation, with a massive infiltration of neutrophils into the lung. Indeed, the persistence of pulmonary bacterial infection despite a vigorous host response is a classical feature of CF disease [1].

In recent years $B$. cepacia has emerged as an important pulmonary pathogen in CF. There is evidence of person-to-person transmission of $B$. cepacia among CF patients and epidemic strains have emerged in North America and the UK $[2,3]$. CF patients colonised with the same B. cepacia strain can have dramatically different responses, ranging from chronic asymptomatic carriage to a rapidly fatal decline in lung function. In either case, however, $B$.

Received 16 June 1998; revised version accepted 5 Aug. 1998.

Corresponding author: Dr A. W. Smith (e-mail: a.w.smith@ bath.ac.uk). cepacia persists in the lungs despite a vigorous neutrophil-dominated inflammatory response.

The principal antibacterial agents from neutrophils are reactive oxygen species and granule products such as the cationic peptide molecules called defensins. Interestingly, one of the few other patient groups susceptible to $B$. cepacia infection comprises those suffering from chronic granulomatous disease (CGD). These patients lack NADPH oxidase and are unable to generate an oxidative respiratory burst. Speert and coworkers have shown that phagocytes from CGD patients killed $P$. aeruginosa whereas $B$. cepacia is resistant [4]. These data indicate that $B$. cepacia is resistant to the cationic peptides of neutrophils and, therefore, that any killing by phagocytes must be mediated by reactive oxygen species. Several reports have indicated that nitric oxide (NO) contributes to the toxicity of reactive oxygen species, perhaps by combination with superoxide anions to form peroxynitrite [5-7]. Its role in the human lung is controversial, as resting human macrophages are reported not to express inducible nitric oxide synthase (iNOS); however, macrophages from patients with inflammatory conditions or infectious diseases consistently do express iNOS [7] and recent work indicates NO production by neutrophils during phagocytosis [8]. The major source of iNOS and NO in the lung is 
likely to be the airway epithelium, where iNOS is expressed constitutively [9]. Studies measuring NO and its breakdown products in $\mathrm{CF}$ patients have yielded conflicting data, indicating increased nitrite in sputum $[10,11]$, a decrease in exhaled NO [12], or no difference in exhaled NO between CF patients and controls $[13,14]$. Very recently, it has been reported that iNOS may not be expressed in the bronchial epithelium of CF patients and this deficiency may contribute to the susceptibility of these patients to bacterial colonisation $[15,16]$.

This study examined the effect of NO generated in vitro on the sensitivity of $B$. cepacia strains to killing by superoxide and $\mathrm{H}_{2} \mathrm{O}_{2}$.

\section{Materials and methods}

\section{Bacterial strains and culture conditions}

$B$. cepacia strains $\mathrm{J} 2315$ and $\mathrm{J} 2552$ were obtained from Professor J. R. W. Govan (University of Edinburgh). $B$. cepacia $\mathrm{J} 2315$ is a highly virulent strain belonging to genomovar III, and has been associated with person-toperson transmission in several centres in the UK and North America. All the other strains were either from the Birmingham (UK) CF clinic or our culture collection. Cultures were grown in succinate minimal medium [17] supplemented with casamino acids (Difco Laboratories) $0.1 \% \mathrm{w} / \mathrm{v}$ at $37^{\circ} \mathrm{C}$ until they reached an $\mathrm{OD}_{470}$ of 0.8 late in the logarithmic phase. The bacteria were harvested by membrane filtration, washed and suspended in $\mathrm{M} 9$ salts solution [18] to an $\mathrm{OD}_{470}$ of 1.0, corresponding to $1 \times 10^{9} \mathrm{cfu} / \mathrm{ml}$.

\section{Generation of reactive oxygen and nitrogen species}

Superoxide $\left(\mathrm{O}_{2}^{-}\right)$was generated from a mixture comprising $10 \mathrm{mM}$ hypoxanthine and xanthine oxidase (Sigma) $100 \mathrm{mU} / \mathrm{ml}$ in $\mathrm{M} 9$ salts solution. Its generation was confirmed by the reduction of ferricytochrome C [19]. The NO donor compound $S$-nitroso- $N$-acetyl penicillamine (Calbiochem, Nottingham) was dissolved in dimethyl sulphoxide to produce a $500 \mathrm{mM}$ stock solution immediately before use; $8.82 \mathrm{M} \mathrm{H}_{2} \mathrm{O}_{2}$, human haemoglobin, bovine erythrocyte superoxide dismutase and bovine liver catalase were all purchased from Sigma.

\section{Bacterial killing assays}

B. cepacia cells were added to the reactive oxygen and nitrogen-generation systems to a final density of $1 \times 10^{7} \mathrm{cfu} / \mathrm{ml}$. Samples were removed over a $90-\mathrm{min}$ period and put into an inactivation medium comprising catalase $10000 \mathrm{U} / \mathrm{ml}$ in $\mathrm{M} 9$ salts solution. A minimum of a 1 in 10 dilution in inactivation medium was performed. After appropriate serial dilution in this inactivation medium, $0.1-\mathrm{ml}$ samples were spread in triplicate on nutrient agar plates, which were incubated for $48 \mathrm{~h}$ at $37^{\circ} \mathrm{C}$. Statistical significances of difference between groups were determined by Student's paired $t$ test on $\log _{10}$ count data or by two-way analysis of variance followed by the Student-Newman-Keules procedure for multiple comparison of group means.

\section{Results}

A cell-free system was chosen to model the role of the reactive oxygen species released during the 'respiratory burst' by activated neutrophils and macrophages, but in the absence of other neutrophil granule products. Timecourse studies indicated no killing of B. cepacia $\mathbf{J} 2315$ by $\mathrm{O}_{2}^{-}$alone over $90 \mathrm{~min}$ (Fig. 1). The NO-generating compound $S$-nitroso- $N$-acetyl penicillamine (5 mM) alone similarly exhibited no antibacterial activity, whereas their combination was rapidly bactericidal (Fig. 1). Addition of haemoglobin $1.5 \mathrm{mg} / \mathrm{ml} \mathrm{com-}$ pletely abrogated this bactericidal effect, whereas addition of superoxide dismutase $5000 \mathrm{U} / \mathrm{ml}$ had no effect (Fig. 1). The activity of the superoxide dismutase was confirmed by its ability to inhibit reduction of ferricytochrome $\mathrm{C}$ by $\mathrm{O}_{2}^{-}$(data not shown).

Following the failure of superoxide dismutase to reduce killing, the effects of catalase $10000 \mathrm{U} / \mathrm{ml}$

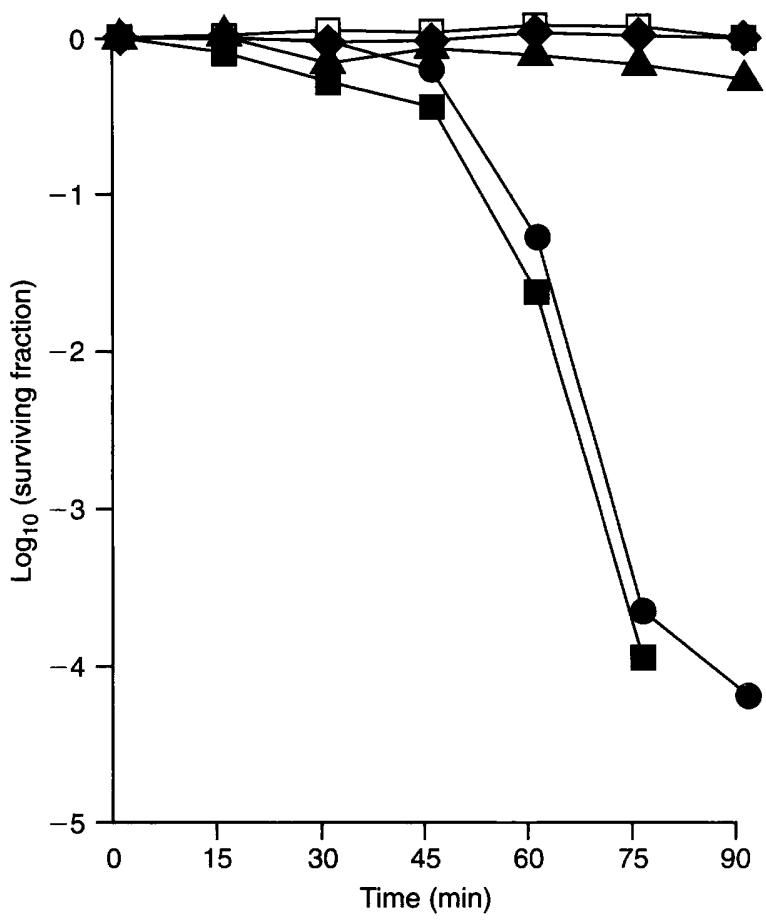

Fig. 1. Survival of B. cepacia J2315 treated with $10 \mathrm{~mm}$ hypoxanthine/xanthine oxidase $0.1 \mathrm{U} / \mathrm{ml}(\diamond), 5 \mathrm{mM} S$ nitroso- $N$-acetyl penicillamine ( $\square$ ), $10 \mathrm{mM}$ hypoxanthine/ xanthine oxidase $0.1 \mathrm{U} / \mathrm{ml}+5 \mathrm{mM} S$-nitroso- $N$-acetyl penicillamine (ס), $10 \mathrm{~mm}$ hypoxanthine/xanthine oxidase $0.1 \mathrm{U} / \mathrm{ml}+5 \mathrm{mM} S$-nitroso- $N$-acetyl penicillamine + superoxide dismutase $5000 \mathrm{U} / \mathrm{ml}(\bullet)$ and $10 \mathrm{mM}$ hypoxanthine/xanthine oxidase $0.1 \mathrm{U} / \mathrm{ml}+5 \mathrm{mM} S$-nitroso- $N$ acetyl penicillamine + haemoglobin $1.5 \mathrm{mg} / \mathrm{ml}(\boldsymbol{\Delta})$. Data are representative of three similar experiments. 
and $5 \mathrm{mM} \mathrm{H}_{2} \mathrm{O}_{2}$ were examined (Fig. 2). Catalase completely abolished the killing mediated by $\mathrm{O}_{2}^{-} / \mathrm{NO}$ mixtures, suggesting that the antibacterial activity is via peroxide and NO. $\mathrm{H}_{2} \mathrm{O}_{2}(5 \mathrm{mM})$ alone was not antibacterial, whereas its combination with $5 \mathrm{mM} S$ nitroso- $N$-acetyl penicillamine achieved a $>1000$-fold decrease in cell viability over $30 \mathrm{~min}$ (Fig. 2). The effects of $\mathrm{H}_{2} \mathrm{O}_{2}$ in combination with $\mathrm{NO}$ on a further 11 B. cepacia strains are shown in Fig. 3; in no case did NO alone achieve any killing (data not shown). A CGD isolate (strain 32) and an environmental isolate (J2552) belonging to genomovar I were killed so efficiently by $\mathrm{H}_{2} \mathrm{O}_{2}$ alone that it was not possible to measure any synergic killing with $\mathrm{NO}$; otherwise, only strains 34 and 40 (both from CF patients) failed to show any significant synergic killing between hydrogen $\mathrm{H}_{2} \mathrm{O}_{2}$ and $\mathrm{NO}$.

\section{Discussion}

B. cepacia is an important pulmonary pathogen in CF patients. Several survival strategies have been proposed for the organism in this patient group, including resistance to non-oxidative neutrophil defence mechanisms [4] and invasion of respiratory epithelial cells [20].

The present study showed that NO could potentiate the toxicity of $\mathrm{H}_{2} \mathrm{O}_{2}$, which is one of the major neutrophil-derived reactive oxygen species. Coupled with the recent observation that there is little or no iNOS activity in CF airway epithelial cells [15], these results may partly explain the predilection of $B$. cepacia for the lungs of CF patients. It is noteworthy that the only other major group of patients susceptible to $B$. cepacia infection comprises those with CGD, whose neutrophils do not mount an oxidative respiratory burst. These data are consistent with the proposal that reactive oxygen and nitrogen species must both be present for successful eradication of the bacterium.

The nature of the reactive antibacterial species formed is unclear. Data from the present study suggest that the combined effects of $\mathrm{NO}$ and $\mathrm{H}_{2} \mathrm{O}_{2}$ are more important than products formed by reaction between $\mathrm{NO}$ and $\mathrm{O}_{2}^{-}$, such as peroxynitrite $\left(\mathrm{ONOO}^{-}\right)$. The failure of superoxide dismutase to abrogate the antibacterial activity of $\mathrm{O}_{2}^{-}$and $\mathrm{NO}$ could be attributed to the faster reaction kinetics between $\mathrm{O}_{2}^{-}$ and $\mathrm{NO}$ than that between $\mathrm{O}_{2}^{-}$and superoxide dismutase [21]; however, the high concentrations of exogenous superoxide dismutase used in this study would be sufficient to compete with $\mathrm{NO}$ for $\mathrm{O}_{2}^{-}$and argue against $\mathrm{O}_{2}^{-}$being the cytotoxic species. Pacelli et al. [22] also found that $\mathrm{NO}$ greatly potentiated $\mathrm{O}_{2}^{-}$mediated killing of Escherichia coli, and that this killing was abolished by catalase but not by superoxide dismutase. Other in-vitro studies have failed to demonstrate synergy between $\mathrm{O}_{2}^{-}$and NO; indeed, NO

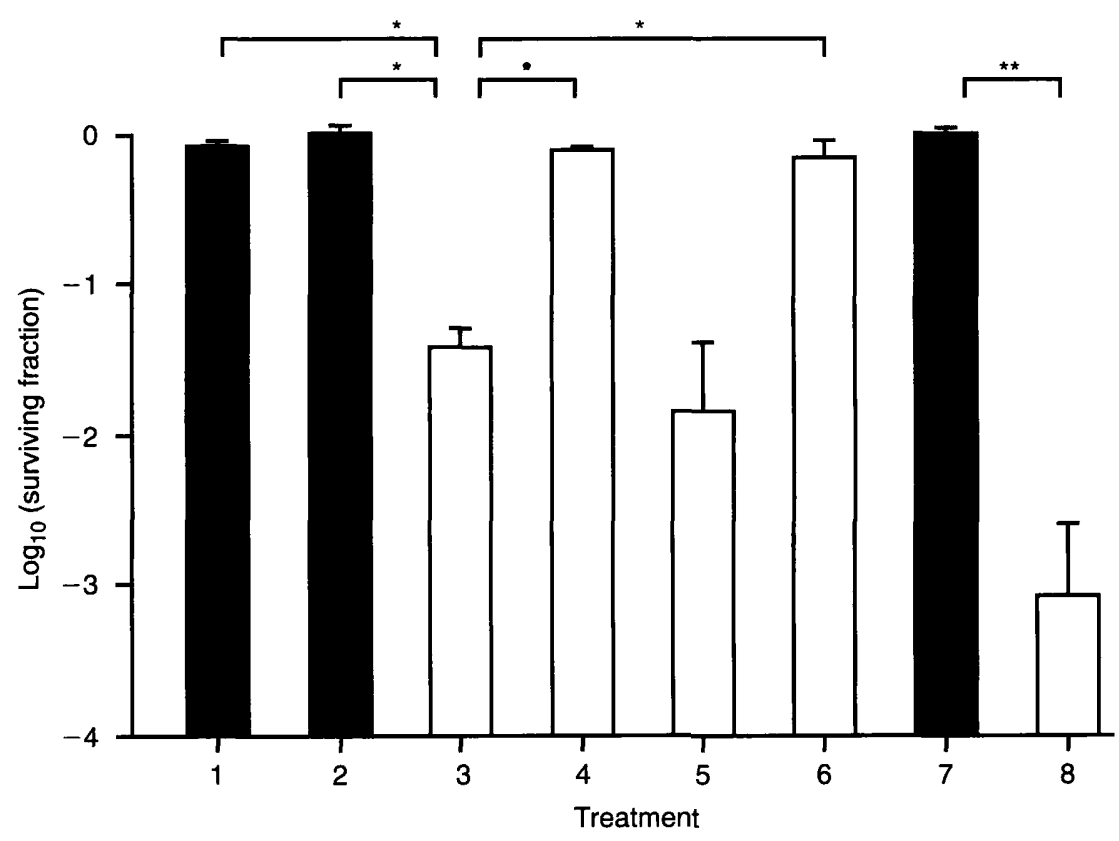

Fig. 2. Survival of $B$. cepacia $\mathrm{J} 2315$ treated for $30 \mathrm{~min}$ with (1) $10 \mathrm{~mm}$ hypoxanthine/xanthine oxidase $0.1 \mathrm{U} / \mathrm{ml}$; (2) $5 \mathrm{mM} S$-nitroso- $N$-acetyl penicillamine; (3) $10 \mathrm{mM}$ hypoxanthine/xanthine oxidase $0.1 \mathrm{U} / \mathrm{ml}+5 \mathrm{mM} S$-nitroso- $N$-acetyl penicillamine; (4) $10 \mathrm{mM}$ hypoxanthine/xanthine oxidase $0.1 \mathrm{U} / \mathrm{ml}+5 \mathrm{mM} \quad S$-nitroso- $N$-acetyl penicillamine + haemoglobin $1.5 \mathrm{mg} / \mathrm{ml}$; (5) $10 \mathrm{mM}$ hypoxanthine/xanthine oxidase $0.1 \mathrm{U} / \mathrm{ml}+5 \mathrm{mM} S$-nitroso- $N$-acetyl penicillamine + superoxide dismutase $5000 \mathrm{u} / \mathrm{ml} ;$ (6) $10 \mathrm{mM}$ hypoxanthine/xanthine oxidase $0.1 \mathrm{U} / \mathrm{ml}+5 \mathrm{mM} S$-nitroso- $N$-acetyl penicillamine + catalase $10000 \mathrm{U} / \mathrm{ml}$; (7) $5 \mathrm{mM} \mathrm{H}_{2} \mathrm{O}_{2}$; (8) $5 \mathrm{mM} \mathrm{H}_{2} \mathrm{O}_{2}+5 \mathrm{mM} S$-nitroso- $N$-acetyl penicillamine. Control cells held in buffer did not show any loss in viability over the 30 -min period. Data are mean $\log _{10}$ surviving fraction and SEM from three independent experiments, each performed in triplicate. Significant differences between treatments: ${ }^{*} \mathrm{p}<0.05 ;{ }^{* *} \mathrm{p}<0.01$. 


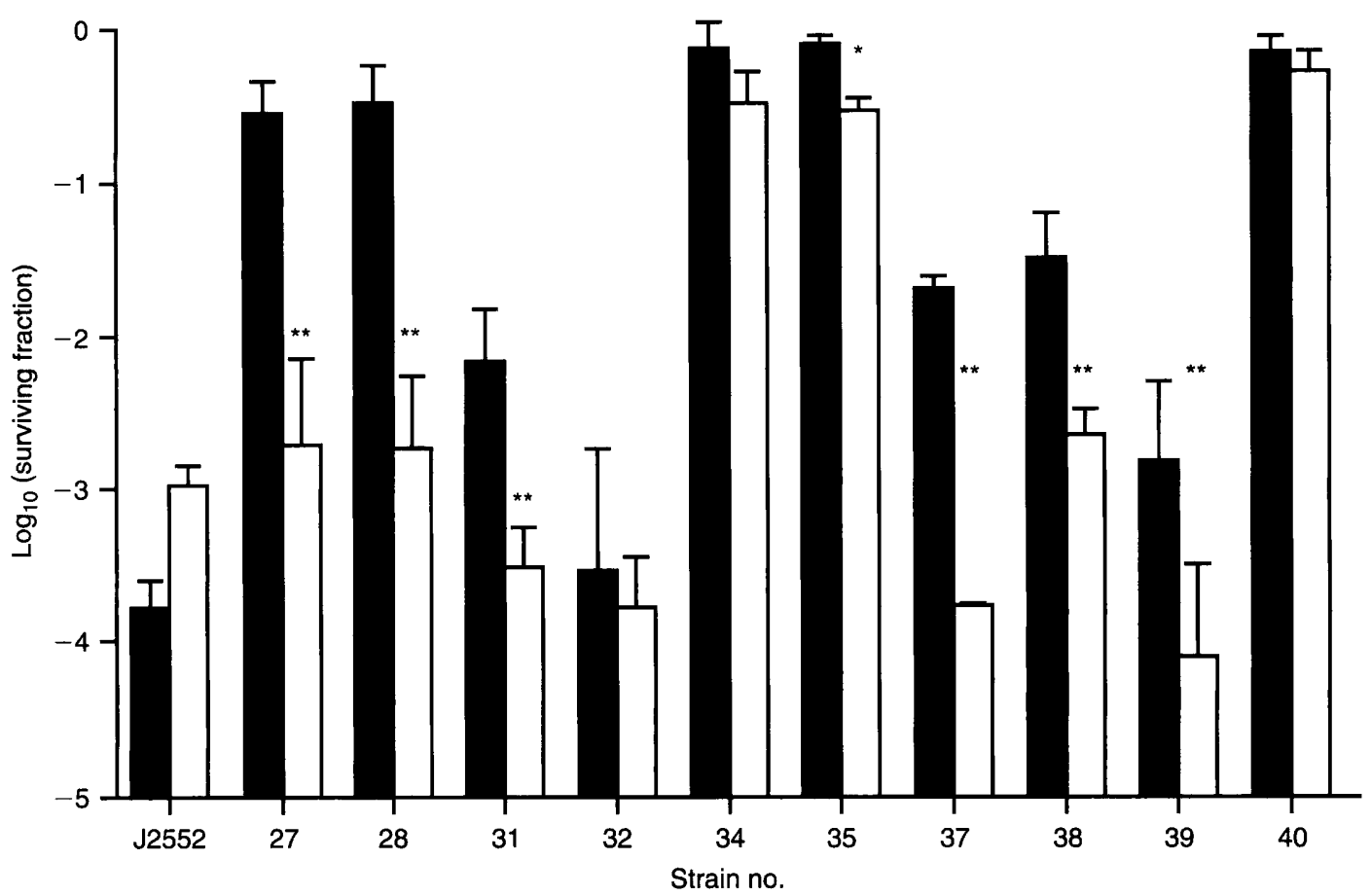

Fig. 3. Survival of a panel of $B$. cepacia strains treated for 30 min with $5 \mathrm{mM} \mathrm{H}_{2} \mathrm{O}_{2}$ (a) and $5 \mathrm{mM} \mathrm{H}_{2} \mathrm{O}_{2}+5 \mathrm{mM} S$ nitroso- $N$-acetyl penicillamine ( $\square$ ). Data are mean $\log _{10}$ surviving fraction and SEM from three independent experiments, each performed in triplicate. ${ }^{*}$ Significantly reduced compared with cells treated with hydrogen peroxide alone, $\mathrm{p}<0.05 ;{ }^{* *} \mathrm{p}<0.01$.

decreased $\mathrm{O}_{2}^{-}$-mediated killing of Staphylococcus aureus at early time points and only enhanced or stabilised killing over prolonged periods of incubation [23]. Whilst numerous in-vivo studies have demonstrated that iNOS and NO contribute to host defence, there are reports of improved outcomes when NOS inhibitors were administered, which have been attributed to the inflammatory effects of NO [7].

To date, there are no reports of the contribution of NO to the survival or killing of $B$. cepacia in the CF mouse model. Ex-vivo experiments reported low recovery of $P$. aeruginosa following inoculation of $500 \mathrm{cfu}$ into the lungs of wild-type mice, whereas there was a 20-fold greater recovery from CF $(\Delta F 508 / \Delta F 508)$ mice [16]. The low recovery from normal lungs was abolished by administration of a NOS inhibitor. Similarly, Gosselin et al. [24] found that administration of the NOS inhibitor, aminoguanidine, to $\mathrm{BALB} / \mathrm{c}$ mice significantly increased the number of $P$. aeruginosa detectable in the lungs 3 days after infection. Both these experiments are consistent with the view that NO protects the lungs from infection.

The targets for the antibacterial activity of $\mathrm{NO}$ and $\mathrm{O}_{2}^{-} / \mathrm{H}_{2} \mathrm{O}_{2}$ are poorly defined, but candidates include the oxidation of sulphydryl groups and lipids, transition metals, DNA damage and nitration of tryosines. $S$-Nitrosothiol compounds, such as the $S$-nitroso- $N$ acetyl penicillamine used in this study, are conventionally viewed as NO donors and are believed to achieve this effect by spontaneous homolytic cleavage, although heterolytic transfer of nitrosium to other sulphydryl centres is also a possible mechanism [25]. The quenching of the $S$-nitroso- $N$-acetyl penicillamine effects by the NO scavenger, haemoglobin [26], supports the notion that NO itself is the key intermediary. Breakage of double-stranded DNA and glutathione depletion by NO have been reported in $E$. coli [22], and the workers responsible for this finding also noted that iron-cofactored superoxide dismutase was susceptible to inactivation by $\mathrm{NO}$ and $\mathrm{H}_{2} \mathrm{O}_{2}$, or $\mathrm{H}_{2} \mathrm{O}_{2}$ alone. Cytoplasmic superoxide dismutase activity is unlikely to protect against extracellular $\mathrm{O}_{2}^{-}$, which does not cross biological membranes. However, it may be a target for freely diffusible species such as NO and $\mathrm{H}_{2} \mathrm{O}_{2}$ and hence render cells susceptible to $\mathrm{O}_{2}^{-}$generated within themselves. A recently described periplasmic superoxide dismutase with copper and zinc as cofactors protected Salmonella typhimurium [27] and Neisseria meningitidis [28] from the toxic effects of $\mathrm{O}_{2}^{-}$generated outside the cell. Mutants lacking this enzyme showed attenuated virulence in animal models. However, periplasmic $\mathrm{CuZn}$ superoxide dismutase seems unlikely to have had any effect in the present study, as exogenously added superoxide dismutase failed to reduce $\mathrm{O}_{2}^{-}$toxicity. We are currently examining catalase levels in the strains used, particularly those that failed to be killed by $\mathrm{NO}$ and $\mathrm{H}_{2} \mathrm{O}_{2}$. Preliminary experiments have demonstrated marked evolution of gas from the resistant strains JL34 and 40 on addition of $\mathrm{H}_{2} \mathrm{O}_{2}$, an intermediate response from strain $\mathrm{J} 2315$ and very little gas 
production from strains JL32 and J2552. These data suggest that differences in sensitivity to $\mathrm{H}_{2} \mathrm{O}_{2}$ are inversely correlated with catalase activity.

In summary, the study showed that NO acts synergically with reactive oxygen species to kill $B$. cepacia in vitro. The observation that iNOS activity may be absent from cells in CF patients provides insight into why this intriguing pathogen survives within the lung despite a vigorous neutrophil-dominated host response.

We thank Dr Tom Kelley for helpful discussions. This work was supported in part by Project Grant PJ411 from the Cystic Fibrosis Trust.

\section{References}

1. Ramsey BW. Drug therapy - management of pulmonary disease in patients with cystic fibrosis. $N$ Engl J Med 1996; 335: $179-188$.

2. Govan JRW, Brown PH, Maddison $\mathrm{J}$ et al. Evidence for transmission of Pseudomonas cepacia by social contact in cystic fibrosis. Lancet 1993; 342: 15-19.

3. Sun L, Jiang R-Z, Steinbach $\mathrm{S}$ et al. The emergence of a highly transmissible lineage of $\mathrm{cbl}^{+}$Pseudomonas (Burkholderia) cepacia causing CF centre epidemics in North America and Britain. Nat Med 1995; 1: 661-666.

4. Speert DP, Bond M, Woodman RC, Curnutte JT. Infection with Pseudomonas cepacia in chronic granulomatous disease: role of nonoxidative killing by neutrophils in host defense. $J$ Infect Dis 1994; 170: 1524-1531.

5. Zhu L, Gunn C, Beckman JS. Bactericidal activity of peroxynitrite. Arch Biochem Biophys 1992; 298: 452-457.

6. Brunelli L, Crow JP, Beckman JS. The comparative toxicity of nitric oxide and peroxynitrite to Escherichia coli. Arch Biochem Biophys 1995; 316: 327-334.

7. MacMicking J, Xie Q-W, Nathan C. Nitric oxide and macrophage function. Annu Rev Immunol 1997; 15: 323-350.

8. Evans TJ, Buttery LDK, Carpenter A, Springall DR, Polak JM, Cohen J. Cytokine-treated human neutrophils contain inducible nitric oxide synthase that produces nitration of ingested bacteria. Proc Natl Acad Sci USA 1996; 93: 9553-9558.

9. Guo FH, De Raeve HR, Rice TW, Stuehr DJ, Thunnissen FBJM, Erzurum SC. Continuous nitric oxide synthesis by inducible nitric oxide synthase in normal human airway epithelium in vivo. Proc Natl Acad Sci USA 1995; 92 7809-7813

10. Linnane SJ, Keatings VM, Costello CM et al. Total sputum nitrate plus nitrite is raised during acute pulmonary infection in cystic fibrosis. Am $J$ Respir Crit Care Med 1998; 158: $207-212$.

11. Francoeur C, Denis $M$. Nitric oxide and interleukin-8 as inflammatory components of cystic fibrosis. Inflammation
1995; 19: $587-598$

12. Grasemann H, Michler E, Wallot M, Ratjen F. Decreased concentration of exhaled nitric oxide (NO) in patients with cystic fibrosis. Pediatr Pulmonol 1997; 24: 173-177.

13. Balfour-Lynn IM, Laverty A, Dinwiddie R. Reduced upper airway nitric oxide in cystic fibrosis. Arch Dis Child 1996; 75 : $319-322$.

14. Lundberg JON, Nordvall SL, Weitzberg E, Kollberg H, Alving $\mathrm{K}$. Exhaled nitric oxide in paediatric asthma and cystic fibrosis. Arch Dis Child 1996; 75: 323-326.

15. Meng Q-H, Springall DR, Bishop AE et al. Lack of inducible nitric oxide synthase in bronchial epithelium: a possible mechanism of susceptibility to infection in cystic fibrosis. $J$ Pathol 1998; 184: 323-331.

16. Kelley $\mathrm{TJ}$, Drumm ML. Inducible nitric oxide synthase expression is reduced in cystic fibrosis murine and human airway epithelial cells: possible involvement in CF-related sodium hyperabsorption and susceptibility to bacterial infection. J Clin Invest 1998; 6: 1200-1207.

17. Meyer JM, Abdallah MA. The fluorescent pigment of Pseudomonas fuorescens: biosynthesis, purification and physicochemical properties. J Gen Microbiol 1978; 107: 319-328.

18. Miller JH. Experiments in molecular genetics. Cold Spring Harbor, NY, Cold Spring Harbor Laboratory Press. 1972.

19. Pick E, Mizel D. Rapid microassays for the measurement of superoxide and hydrogen peroxide production by macrophages in culture using an automatic enzyme immunoassay reader $J$ Immunol Methods 1981; 46: 211-226.

20. Burns JL, Jonas M, Chi EY, Clark DK, Berger A, Griffith A. Invasion of respiratory epithelial cells by Burkholderia (Pseudomonas) cepacia. Infect Immun 1996; 64: 4054-4059.

21. Beckman JS, Chen J, Ischiropoulos H, Crow JP. Oxidative chemistry of peroxynitrite. Methods Enzymol 1994; 233 229-240.

22. Pacelli R, Wink DA, Cook JA et al. Nitric oxide potentiates hydrogen peroxide-induced killing of Escherichia coli. J Exp Med 1995; 182: 1469-1479.

23. Kaplan SS, Lancaster JR, Basford RE, Simmons RE. Effect of nitric oxide on staphylococcal killing and interactive effect with superoxide. Infect Immun 1996; 64: 69-76.

24. Gosselin D, DeSanctis J, Boulé M, Skamene E, Matouk C, Radzioch D. Role of tumor necrosis factor alpha in innate resistance to mouse pulmonary infection with Pseudomonas aeruginosa. Infect Immun 1995; 63: 3272-3278.

25. Fang FC. Mechanisms of nitric oxide-related antimicrobial activity. J Clin Invest 1997; 99: 2818-2825.

26. Rioux F, Petitclerc E, Audet R, Drapeau G, Fielding RM, Marceau F. Recombinant human hemoglobin inhibits both constitutive and cytokine-induced nitric oxide-mediated relaxation of rabbit isolated aortic rings. $J$ Cardiovasc Pharmacol 1994; 24: 229-237.

27. Farrant JL, Sansone A, Canvin JR et al. Bacterial copper- and zinc-cofactored superoxide dismutase contributes to the pathogenesis of systemic salmonellosis. Mol Microbiol 1997; 25 . 785-796.

28. Wilks KE, Dunn KRL, Farrant JL et al. Periplasmic superoxide dismutase in meningococcal pathogenicity. Infect Immun 1998, 66: $213-217$. 